\title{
Plasma viscosity and whole blood viscosity as diagnostic tools of blood abnormalities by using simple syringe method
}

\author{
Mohamed A. Elblbesy ${ }^{1,2}$ \\ Correspondence: mimizizo@yahoo.com

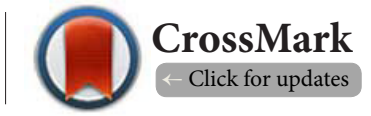 \\ 'Department of Medical Laboratory Technology, Faculty of Applied Medical Science, University of Tabuk, Saudi Arabia. \\ ${ }^{2}$ Department of Medical Biophysics, Medical Research Institute, Alexandria University, Egypt.
}

\begin{abstract}
There are many different methods for the assessment of whole blood viscosity, but not every pathology unit has equipment for any of the methods. Whole blood viscosity can be extrapolated from haematocrit and total serum proteins. The objective of this work is to develop a simple method by which clinical laboratory workers can easily extrapolate whole blood and plasma viscosity. Another objective is to examine if the new technique can be used to measure blood and plasma viscosity under different conditions. In the present study, simple syringe method was used to measure relative blood viscosity (RBV) and relative plasma viscosity (RPV). A volume of $2 \mathrm{ml}$ of whole blood was allowed to flow freely through a syringe and the time of flow was estimated and then divided by the time of flow of the standard to obtain RBV. In the same sequence RPV was measured using plasma. The correlation between RBV and some blood parameters in both control and anemia cases were examined in order to make sure of the accuracy of the method used. Statistically significant difference in measured values of RBV between control and anemia cases was obtained, but not for RPV values. A strong direct correlation was observed for the relations of RBV and other blood parameters in both control and anemia cases.
\end{abstract}

Keywords: Syringe method, blood viscosity, plasma viscosity, RBV, RPV

\section{Introduction}

The study of hemorheology has been of great interest in the fields of biomedical engineering and medical research for many years. Hemorheology plays an important role in atherosclerosis Hemorheological properties of blood include whole blood viscosity, plasma viscosity, hematocrit, RBC definability and aggregation, and fibrinogen concentration in plasma. Although a number of parameters such as pressure, lumen diameter, whole blood viscosity, compliance of vessels, peripheral vascular resistance are well-known physiological parameters that affect the blood flow, the whole blood viscosity is also an important key physiological parameter. However, it's significance has not been fully appreciated yet [1].

A number of researchers measured blood viscosities in patients with coronary arterial disease such as ischemic heart disease and myocardial infarction [2]. They found that the viscosity of whole blood might be associated with coronary arterial diseases. In addition, a group of researchers reported that whole blood viscosity was significantly higher in patients with peripheral arterial disease than that in healthy controls [3]. Other researchers investigated correlation between the hemorheological parameters and stroke [4]. They reported that stroke patients showed two or more elevated rheological parameters, which included whole blood viscosity, plasma viscosity, red blood cell (RBC) and plate aggregation, $\mathrm{RBC}$ rigidity, and hematocrit. It was also reported that both whole blood viscosity and plasma viscosity were significantly higher in patients with essential hypertension than in healthy ones, whereas RBC deformability was decreased. Others conducted hemorheological studies to detect the relationships between whole blood viscosity and smoking, age, and gender $[5,6]$. They found that smoking and aging might cause the elevated blood viscosity. In addition, it was reported that male blood possessed higher blood viscosity, RBC aggregability, and RBC 
Mohamed A. Elblbesy, Medical Instrumentation 2014,

rigidity than premenopausal female blood, which may be attributed to monthly blood-loss [7].

Much research has been performed to formulate a theory that accounts completely for the viscous properties of blood, and some of the key determinants have been identified. The four main determinants of whole blood viscosity are (1) plasma viscosity, (2) hematocrit, (3) RBC deformability and aggregation, and (4) temperature. The first three factors are parameters of physiologic concern because they pertain to changes in whole blood viscosity in the body Especially, the second and third factors, hematocrit and RBC aggregations, mainly contribute to the non-Newtonian characteristics of shear-thinning viscosity and yield stress [8].

Plasma is blood from which all cellular elements have been removed. It had established that plasma behaves like a Newtonian fluid. Careful tests inducted using both rotating and capillary tube viscometers over a range of shear rate (i.e., from 0.1 to $1200 \mathrm{~s}^{-1}$ ) found no significant departures from linearity. Therefore, its viscosity is independent of shear rate [9].

Viscosity of whole blood varies directly with hematocrit at all cell concentrations above $10 \%$. Since studies have shown normal plasma to be a fluid, the non Newtonian features of human blood undoubtedly come from suspended cells in blood. The rheological properties of suspensions correlate highly with the concentrations of suspended particles. In blood the most important suspended particles are the red blood cells (RBC). Hematocrit is the most important determinant of whole blood viscosity. The effect of hematocrit on blood viscosity has become well documented $[10,11]$.

Deformability is a term used to describe the tactual response of a body or cell to applied forces. At 50\% concentration, the viscosity of a suspension of rigid spheres reaches almost infinity so that the suspension is not able to flow. On the contrary, normal blood remains fluid even at a hematocrit of $98 \%$, on account of the deformability of its RBCs [11].

Since red cells do not have a nucleus, they behave like a fluid drop. Accordingly, human RBCs have the ability to form aggregates known as rouleaux. Rouleaux formation is highly dependent on the concentration of fibrinogen and globulin in plasma. Note that bovine blood does not form rouleaux because of absence of fibrinogen and globulin in plasma [12].

This study aims at studying the influence in relative plasma viscosity (RPV) and relative blood viscosity (RBV) due to iron deficiency anemia using a very simple and low cost technique enabling the laboratory workers to asses BRV and PRV with quick and accurate method. The correlations between blood parameters, RPV and RBV will be studied through this work.

\section{Materials and methods Sample collection}

Blood sample were collected from volunteers with the same gender and age range between 17 to 25 years. $5 \mathrm{ml}$ of blood from each was collected. CBC was done for all samples with hemoglobin less than $11.5 \mathrm{~g} / \mathrm{dl}, \mathrm{MCV}$ below $80 \mathrm{um}^{3}(\mathrm{FL})$ were considered as iron deficiency anemia. The other normal samples were used as control. Ten samples for each iron deficiency anemia and control were collected. The blood sample was divided into three parts. One part was used in $C B C$, and the other two parts were used in determination of RBV and RPV. For determination of RPV blood was centrifuged in order to separate plasma.

\section{Blood tests}

Blood samples were obtained following standard methods by well trained nurses to prevent hemolysis and clot formation. Blood samples were collected with an anticoagulant. Blood samples were then transferred under appropriate conditions, avoiding exposure to high or low temperature, to laboratory where blood tests were performed (CBC). $C B C$ was done using auto analyzer.

\section{Whole blood and plasma viscosity measurements}

Whole blood and plasma viscosity were measured using low cost syringe method in order to measure relative plasma viscosity (RPV), and relative whole blood viscosity (RBV). Two $\mathrm{ml}$ of the whole blood sample was collected with syringe. The syringe was fixed in vertical position, then the plunger of the syringe was removed and the blood was allowed to flow freely. The time of flow of the blood was observed using stopwatch. Schematic diagram of simple syringe method is showed in Figure 1. RBV was calculated using the following equation:

$$
\mathrm{RBV}=\frac{t_{\text {blood }}}{t_{\text {water }}}
$$

Where $t_{\text {blood }}$ is the time of flow of $2 \mathrm{ml}$ of whole blood, and $t_{\text {wate }}$ is the time of flow of $2 \mathrm{ml}$ of distilled water which was used as a standard.

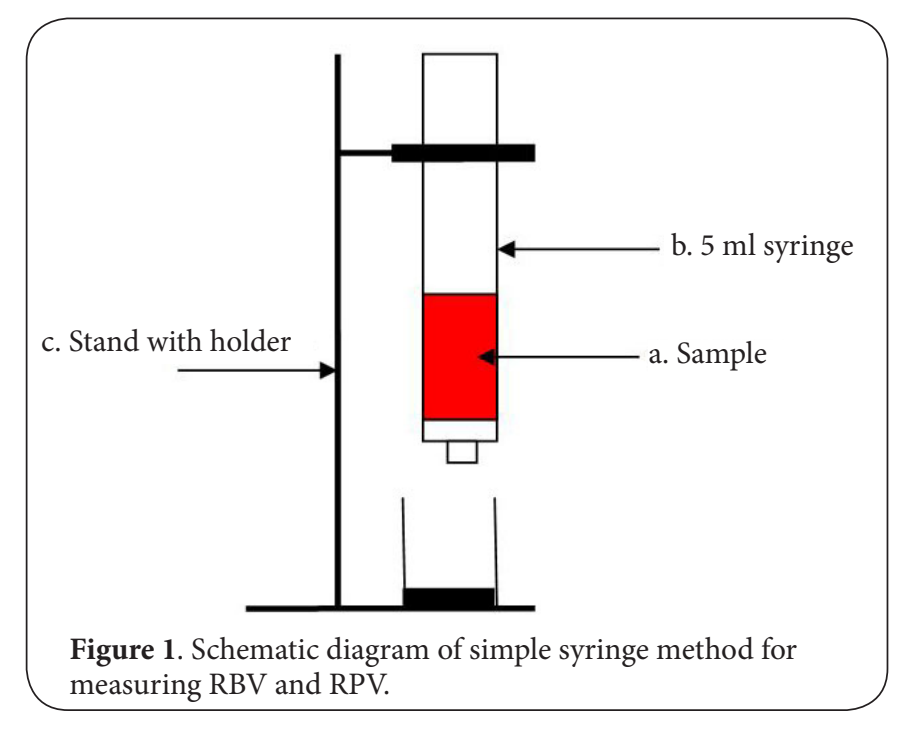


The blood was centrifuged at $3000 \mathrm{rpm}$ in order to separate the plasma. Then RPV was measured with the same procedure mentioned above. RPV was calculated by the following equation:

$$
\mathrm{RPV}=\frac{t_{\text {Plasma }}}{t_{\text {water }}}
$$

Where $t_{\text {blood }}$ is the time of flow of $2 \mathrm{ml}$ of plasma, and $t_{\text {water }}$ is the time of flow of $2 \mathrm{ml}$ of distilled water which was used as a standard.

\section{Statistical analyses}

For each sample the measurements of RBV and RPV were repeated ten times. The values of RBV and RPV were represented as the mean \pm SD. To study the correlations between the RBV and blood parameters, $R^{2}$ was computed using Microsoft office Excel 2007. For $R^{2}>0.5$ it was used as indication for strong correlation, $\mathrm{R}^{2}=0.5$ for moderate correlation and $\mathrm{R}^{2}<0.5$ for weak correlation. Jarque-Bera test was done to test the normality of the data obtained. In order to study the statistical significance of the results the two sample unpaired $t$-test had been done. $p \leq 0.05$ had been taken as the significance limit.

\section{Results}

The mean value of the RBV of control was $5.5 \pm 0.05$ and for anemia was $5.2 \pm 0.07$. RBV values for control and anemia were statistically significance due to $p<0.05$. There was a decrease in RBV in case of anemia when compared with control. The value of RBV was reduced by about $5 \%$ from control. RPV for control was $1.68 \pm 0.04$ and $1.29 \pm 0.15$ for anemia. RPV also decreased as compared with control but the decrease in its value about $24 \%$ from control. The values of RPV for control in comparison of the values of RPV for anemia were statistically insignificance due to $p>0.05$.

For both control and anemia, the relation between RBV and HCT was directly proportional and strong correlation was observed $\left(R^{2}=0.67\right.$ and 0.68 for control and anemia respectively). Figure 2 shows the relation between RBV and HCT. The decrease in HCT \% was clearly observed in anemia. Also the decrease in the value of RBV in anemia was observed in comparison with control.

Direct proportionality and strong correlation $\left(R^{2}=0.72\right.$ and 0.6 for control and anemia respectively) was observed for the relation between RBV and HGB, Figure 3. In comparison with control HGB in anemia is much less than in control.

Also, strong correlation $\left(\mathrm{R}^{2}=0.6\right.$ and 0.7 for control and anemia respectively) was observed for the relation between RBC count and RBV. This was showed in Figure 4.

Linear relation between RBV and other blood parameters was observed as indicated in (Figures 2-4).

\section{Discussion}

The proposed link between iron deficiency and hyperviscosity
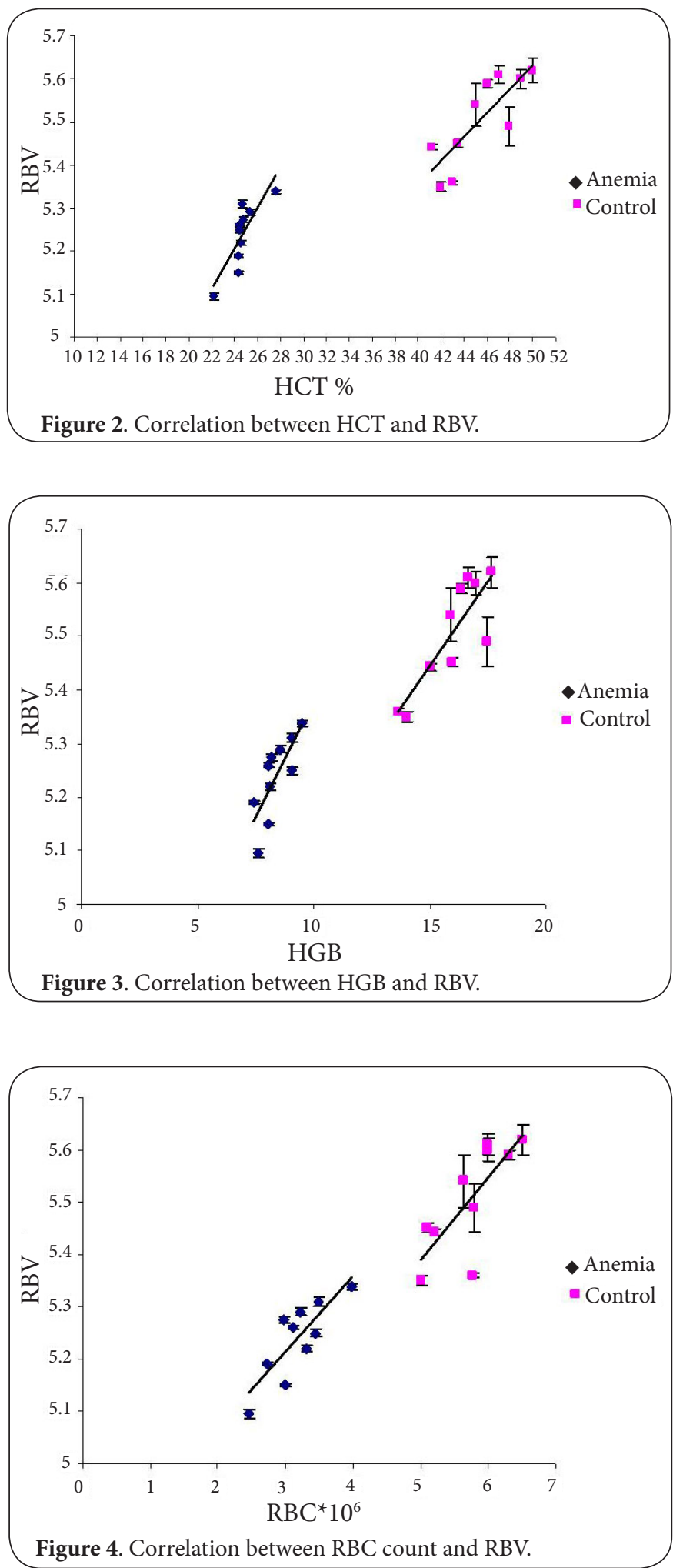

is based on studies with considerable differences in subjects and methods that reach inconsistent conclusions. Comparisons are also difficult because whole blood viscosity cannot be 
Mohamed A. Elblbesy, Medical Instrumentation 2014,

http://www.hoajonline.com/journals/pdf/2052-6962-2-5.pdf

doi: 10.7243/2052-6962-2-5

quantified as a single entity. Many studies were conducted in polycythemic subjects, unlike cyanotic patients with secondary erythrocytosis, have elevated leukocyte and platelet counts that contribute significantly to hyperviscosity and symptoms [13-16]. Our finding that iron deficiency decrease RBV and RPV is in agreement with previous studies [13-16]. Because of iron's key role in $\mathrm{Hb}$ synthesis, reduced availability of iron hinders erythropoiesis. Because Hct is the strongest determinant of viscosity, it is logical to suspect that lower viscosity, rather than higher, will eventually result from limited iron $[17,18]$. The second most powerful determinant of viscosity is fibrinogen via its role in forming temporary bonds that facilitate RBC aggregation [19]. Phlebotomy-induced iron deficiency has been shown to lower fibrinogen levels in select patients [20]. This is lending to further support to our finding that iron deficiency actually decreases RBV and RPV.

The many studies that describe the influence of percentage hematocrit upon blood viscosity are essentially similar in their conclusions as to the degree of effect red cell concentrations have upon viscosity values $[\mathbf{2 1 , 2 2 ] . ~ I n ~ t h e ~ p r e s e n t ~ s t u d y ~ i t ~ w a s ~}$ shown a strong correlation between RBV and HCT which in harmony with the previous studies.

Blood viscosity is affected by the alteration in the concentration of biochemical factors in plasma. For instance, red blood cell aggregability which is induced by fibrinogen, is well documented. Similarly, red blood cell filterability/deformability and rigidity are not only influenced by external and internal constituents of red blood cells but to a larger extent by the membrane characteristics [23]. We have selected hemoglobin along with haematocrit as major factors contributing to blood viscosity. Our results showed a strong correlation between $\mathrm{RBV}$ and hemoglobin concentration which is in according of the previous study [23].

Blood viscosity has been acknowledged as a factor in all metabolic diseases. Gender factor is not included in the arithmetic formula. This is explainable by the observation from other methods of blood viscosity measurement that blood viscosity level may be higher in men compared to women, but not correcting for haematocrit. That is, even in tandem proteinaemia status, a woman may present lower WBV level due to the factor of lower normal range for haematocrit [24]. Our finding shows a dependency of the RBV on haematocrit which in agreement with many studies in this field.

\section{Conclusion}

It has been recommended that blood viscosity should be measured routinely in medical practice. However, the test has yet to be accessible from every laboratory, and especially in rural areas. What this article contributes is a simple tool that enables medical laboratory workers to assess blood viscosity using very low cost method. Beside the method adopted in this study, different methods exist for the determination of blood and plasma viscosity and associated with this is different normal values. Further study is proposed to investigate how the reference ranges reported here compares with the reference ranges of other blood viscosity methods.

\section{Competing interests}

The author declares that he has no competing interests.

Publication history

Editor: Errikos Ventouras, Technological Educational Institution of Athens, Greece.

EIC: Domenico Rubello, Padova University, Italy.

Received: 24-Jun-2014 Final Revised: 30-Aug-2014

Accepted: 22-Sep-2014 Published: 29-Sep-2014

\section{References}

1. Kensey K.R and Cho Y.I. The Origin of Atherosclerosis (An Introduction to Hemodynamics). EPP Medica, New Jersey. 2001; 1:459-471. | Book

2. Jan KM, Chien S and Bigger JT, Jr. Observations on blood viscosity changes after acute myocardial infarction. Circulation. 1975; 51:107984. | Article | PubMed

3. Briley DP, Giraud GD, Beamer NB, Spear EM, Grauer SE, Edwards JM, Clark WM, Sexton GJ and Coull BM. Spontaneous echo contrast and hemorheologic abnormalities in cerebrovascular disease. Stroke. 1994; 25:1564-9. | Article | PubMed

4. Leiper JM, Lowe GD, Anderson J, Burns P, Cohen HN, Manderson WG, Forbes CD, Barbenel JC and MacCuish AC. Effects of diabetic control and biosynthetic human insulin on blood rheology in established diabetics. Diabetes Res. 1984; 1:27-30. | Article | PubMed

5. Yarnell JW, Sweetnam PM, Rumley A and Lowe GD. Lifestyle and hemostatic risk factors for ischemic heart disease : the Caerphilly Study. Arterioscler Thromb Vasc Biol. 2000; 20:271-9. | Article | PubMed

6. Guyton A.C and Hall J.E. Textbook of Medical Physiology, 9th edition. W.B. Sanders Company, Philadelphia. 1996; 14:169. I Pdf

7. Cinar Y, Demir G, Pac M and Cinar AB. Effect of hematocrit on blood pressure via hyperviscosity. Am J Hypertens. 1999; 12:739-43. | Article I PubMed

8. Ciuffetti G, Mercuri M, Mannarino E, Robinson MK, Lennie SE and Lowe G. Peripheral vascular disease. Rheologic variables during controlled ischemia. Circulation. 1989; 80:348-52. I Article I PubMed

9. Fung Y.C. Biomechanics: Mechanical Properties of Living Tissues. Springer. 1993; 3:60. I Article

10. Hill MA, Court JM and Mitchell GM. Blood rheology and microalbuminuria in type I diabetes mellitus. Lancet. 1982; 2:985. | Article | PubMed

11. Walawender WP, Chen TY and Cala DF. An approximate Casson fluid model for tube flow of blood. Biorheology. 1975; 12:111-9. | PubMed

12. Birgegard G, Carlsson M, Sandhagen B and Mannting F. Does iron deficiency in treated polycythemia vera affect whole blood viscosity? Acta Med Scand. 1984; 216:165-9. I Article I PubMed

13. Milligan DW, MacNamee R, Roberts BE and Davies JA. The influence of iron-deficient indices on whole blood viscosity in polycythaemia. $\mathrm{Br} J$ Haematol. 1982; 50:467-71. | Article | PubMed

14. Kontras SB, Bodenbender JG, Craenen J and Hosier DM. Hyperviscosity in congenital heart disease. J Pediatr. 1970; 76:214-20. | Article | PubMed

15. Rampling MW. Hyperviscosity as a complication in a variety of disorders. Semin Thromb Hemost. 2003; 29:459-65. I Article I PubMed

16. Wedemeyer AL, Edson JR and Krivit W. Coagulation in cyanotic congenital heart disease. Am J Dis Child. 1972; 124:656-60. | Article | PubMed

17. Replogle RL, Meiselman HJ and Merrill EW. Clinical implications of blood rheology studies. Circulation. 1967; 36:148-60. | Article I PubMed

18. Facchini FS and Saylor KL. Effect of iron depletion on cardiovascular risk factors: studies in carbohydrate-intolerant patients. Ann N Y Acad Sci. 2002; 967:342-51. | Article | PubMed 
Mohamed A. Elblbesy, Medical Instrumentation 2014,

http://www.hoajonline.com/journals/pdf/2052-6962-2-5.pdf

19. Pirofsky B. The determination of blood viscosity in man by a method based on Poiseuille's law. J Clin Invest. 1953; 32:292-8. | Article | PubMed Abstract I PubMed Full Text

20. Annapurna V, Puniyani R R and Gupte R V. Clinical Hemorheology. New Horizons. New Delhi: London: New Age International. 1996; 10:95-101.

21. Cecchi $E$, Mannini $L$ and Abbate R. [Role of hyperviscosity in cardiovascular and microvascular diseases]. G Ital Nefrol. 2009; 26 Suppl 46:20-9. | PubMed

22. Tamariz LJ, Young JH, Pankow JS, Yeh HC, Schmidt MI, Astor B and Brancati FL. Blood viscosity and hematocrit as risk factors for type 2 diabetes mellitus: the atherosclerosis risk in communities (ARIC) study. Am J Epidemiol. 2008; 168:1153-60. | Article | PubMed Abstract | PubMed Full Text

23. Lee BK, Durairaj A, Mehra A, Wenby RB, Meiselman HJ and Alexy T. Microcirculatory dysfunction in cardiac syndrome $X$ : role of abnormal blood rheology. Microcirculation. 2008; 15:451-9. | Article | PubMed

24. Larcan A, Stoltz JF and Gaillard S. [Blood viscosity. Measurement and applications (hyper--and hypoviscosity syndromes) (author's transl)]. Nouv Presse Med. 1981; 10:1411-5. | Article | PubMed

\section{Citation:}

Elblbesy MA. Plasma viscosity and whole blood viscosity as diagnostic tools of blood abnormalities by using simple syringe method. Med Instrum. 2014; 2:5.

http://dx.doi.org/10.7243/2052-6962-2-5 